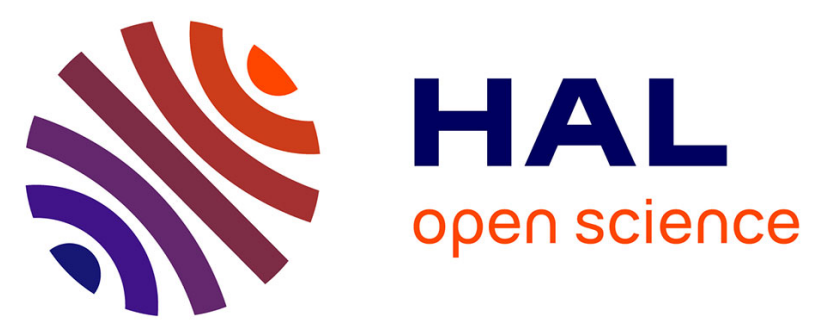

\title{
Employee ownership: A theoretical and empirical investigation of management entrenchment vs. reward management
}

Nicolas Aubert, Guillaume Garnotel, André Lapied, Patrick Rousseau

\section{- To cite this version:}

Nicolas Aubert, Guillaume Garnotel, André Lapied, Patrick Rousseau. Employee ownership: A theoretical and empirical investigation of management entrenchment vs. reward management. Economic Modelling, 2014, 10.1016/j.econmod.2013.12.011 . halshs-01256766

\section{HAL Id: halshs-01256766 \\ https://shs.hal.science/halshs-01256766}

Submitted on 18 Jan 2016

HAL is a multi-disciplinary open access archive for the deposit and dissemination of scientific research documents, whether they are published or not. The documents may come from teaching and research institutions in France or abroad, or from public or private research centers.
L'archive ouverte pluridisciplinaire HAL, est destinée au dépôt et à la diffusion de documents scientifiques de niveau recherche, publiés ou non, émanant des établissements d'enseignement et de recherche français ou étrangers, des laboratoires publics ou privés. 


\title{
Employee Ownership: A Theoretical and empirical investigation of Management Entrenchment vs. Reward Management ${ }^{1}$
}

\author{
November 2013 \\ Nicolas AUBERT ${ }^{2}$ \\ Guillaume GARNOTEL ${ }^{3}$ \\ André LAPIED ${ }^{4}$ \\ Patrick ROUSSEAU ${ }^{5}$
}

\begin{abstract}
:
Employee ownership is often used as a reward management tool but also as an entrenchment mechanism. The literature suggests that good managers use employee ownership as a reward management tool, whereas bad managers implement it for entrenchment, thus suggesting the existence of an equilibrium level of employee ownership. The contributions of this paper are both theoretical and empirical. Theoretically, this paper fills a gap in the published research by taking into account both positive and negative outcomes of employee ownership. Our model produces three main conclusions: (i) Low-performing managers use employee ownership as an entrenchment mechanism (ii) that increases the signaling cost of employee ownership for high-performing managers. (iii) We suggest that employee ownership should not be left only to the management's discretion because both types of managers have an incentive to implement employee ownership. Our empirical study investigates how employee ownership affects management tenure. This study takes into account the two main motives for employee ownership examined by the model (i.e., management entrenchment and reward management). We find a positive relationship between employee ownership and management tenure. This result provides new evidence that employee ownership can be used as an entrenchment mechanism.
\end{abstract}

Keywords: employee ownership, corporate governance, management entrenchment, reward management.

JEL classification: G11, G32, G34, J33.

\footnotetext{
${ }^{1}$ We thank participants of the MFA annual meeting, the AFFI conference, the international corporate governance conference and the international finance conference for their comments.

2 niaubert@gmail.com. Toulon University (GRM) and Inseec.

3 ggarnotel@groupeinseec.com. INSEEC Business School.

4 a.lapied@univ-amu.fr. Aix-Marseille University (Aix-Marseille School of Economics), CNRS EHESS.

${ }^{5}$ patrick.rousseau@iae-aix.com. Aix-Marseille University, IAE Aix-en-Provence, CERGAM.
} 


\section{Introduction}

The academic literature regards employee ownership as a two-edged sword. On the one hand, employee ownership is often used as a reward management tool to enhance corporate performance through its incentive effects. On the other hand, employee ownership is also used as a management entrenchment mechanism that results in poor corporate governance because of the potential collusion between employee owners and management. In the case of a hostile takeover bid, employee owners usually vote to maintain the incumbent management team. The hostile takeover bid by Shamrock Holdings on Polaroid in the late 1980s triggered the use of employee ownership as an anti-takeover device. According to Rauh (2006), this strategy was later imitated by many other US companies. Defensive employee ownership plans were also used in Europe by Société Générale against BNP Paribas in 2000 and by Gucci against Louis Vuitton Moët Hennessy in 1999. Several motivations exist for managers and employees to favor employee ownership, and these motivations will be analyzed in the next section. Blasi (1988) remarked that employee ownership could be regarded as a revolution or as a rip-off. Employee ownership could be regarded as a revolution when it improves corporate performance and leads to better workplace satisfaction. However, employee ownership is a rip-off when it is used as a management entrenchment mechanism.

The decision of implementing and developing employee ownership always lies with management. Managers would have two motivations to offer company stock to employees: to incentivize the employees or to keep their job. These conflicting points lead us to investigate management's motivations to offer company stock to employees. Although these motivations are unobservable, they can be inferred by observing corporate expenditures dedicated to employee ownership. These expenditures can take the form of a discount on company stock prize or of matching contributions in company stock. The latter mechanism is widely used in the US 401(k) plan, for instance where employers make their matching contributions conditional on employees investing in the company stock. Matching contributions are responsible for a substantial amount of own-company stock in 401(k) plans. Benartzi (2001), Holden and VanDerhei (2001) and Brown et al (2006) find that employees' investment in company stock is higher in firms where the employer directs matching contribution into company stock; in particular, the fraction of employees' own contribution allocated to company stock is calculated to be nearly ten percent higher on average. Benartzi (2001) argues that employees tend to consider management's matching contribution in company stock as an implicit investment advice and calls this phenomenon the "endorsement effect". In this paper, we consider that matching contributions can reveal management type. From this standpoint, management discloses its management type by choosing the amount of company stock granted to employees. Some managers use employee ownership to reward their employees, whereas others use it as an entrenchment mechanism.

Our paper thus provides theoretical and empirical findings. From a theoretical standpoint, it fills a gap by taking into account both positive and negative aspects of employee ownership, which are empirically emphasized. The theoretical model generates three main conclusions: (i) Low-performing managers use employee owner- 
ship as an entrenchment mechanism, and (ii) the low-performing managers' strategy increases the signaling cost of employee ownership for high-performing managers. Employee ownership is thus used as an entrenchment mechanism by low-performing managers and as a signal by high-performing managers. These conclusions imply that low-performing managers have an interest in imitating the high-performing managers and vice versa. (iii) To solve this problem, we include prior commitment in the model which means, from an empirical point of view, that employee ownership should not only be left to management's discretion.

By taking into account the two motives of employee ownership examined in the model (i.e., management entrenchment and reward management), our empirical study investigates how employee ownership affects management tenure. Whereas other empirical studies show that employee ownership is a powerful tool to deter takeover (see Rauh, 2006 and Brown et al., 2006 for recent evidence) or a powerful reward management tool (Kruse et al., 2010 and 2012), our empirical study considers both sides of employee ownership and how employee ownership affects management tenure. We collect data on managers who were in their position between 1998 and 2011 in a sample of French listed companies. Controlling for several variables, we find a positive relationship between employee ownership and management tenure. This result provides new evidence that employee ownership can be used as an entrenchment tool.

This paper proposes a sequential game where a risk-neutral manager grants company stock to his risk-averse employee. The remainder of the paper is organized as follows. Section 2 analyzes the literature on incentive effects of employee ownership and its implication for corporate governance. Section 3 presents the model set-up. In section 4, we identify the circumstances in which employee ownership is used as an entrenchment tool and as a reward mechanism and consider several extensions. Section 5 presents comparative static analyses. Section 6 displays the results of an empirical study investigating the relationship between employee ownership and management tenure. The data cover all managers' tenure in companies listed in the French SBF 120 from 1998 to 2011. Section 7 offers concluding remarks. All proofs are presented in the appendix.

\section{Literature}

The theoretical and empirical literature has always been controversial regarding employee ownership outcomes. Both the potential positive and negative effects of employee ownership are still discussed. At the employee level, the effect of employee ownership on job attitudes is debated. At the corporate level, the relationship between employee ownership and corporate governance remains unclear. However, two points of view emerge: employee ownership positively affects corporate performance through enhanced job attitudes, and employee ownership has negative effects on corporate governance.

One body of literature on employee stock ownership focuses on positive effects on employee behavior. These studies tested how employee ownership affects work attitudes with regard to implication, involvement, satisfaction, turnover and turnover intention. Klein (1987) identified three perspectives to explain the effects of employee 
stock ownership on employee behavior: intrinsic, instrumental and extrinsic. The intrinsic perspective states that employee ownership per se can increase employee commitment to the organization and job satisfaction. The instrumental perspective states that employee-owner satisfaction and commitment are derived from the participation in decision-making. The extrinsic perspective states that employee stock ownership is motivating when it is financially rewarding. Most of the empirical literature suggests that this last perspective explains the best employee owners' positive attitudes (French, 1987; Klein, 1987; Rosen et al., 1986; Buchko 1992, 1993; Gamble et al., 1999; Kruse et al., 2010, 2012). Collective incentive systems such as employee ownership are often accused of stimulating free-riding behaviors. This is a major criticism against employee ownership. Kruse et al. (2010) surveyed more than 40,000 employees, where the sample was representative of the entire US working population. They investigated the relationship between shared capitalism practices, i.e., employee ownership, gain sharing, profit sharing and broad-based stock options, and several workplace outcomes, and they found that shared capitalism neutralizes free-riding behavior. Because employee stock ownership is a way to motivate employees, it affects corporate performance. In the literature, performance is measured in terms of productivity and profitability. Kruse and Blasi (1997) reviewed all of the empirical tests of employee stock ownership on performance. To summarize all the findings available, Kruse (2002) states that the empirical literature considers employee stock ownership as having either a positive or null effect on performance. Another body of literature on employee stock ownership focuses on its negative effects on corporate governance. Employee stock ownership is regarded as a powerful entrenchment tool because it reduces the probability of a takeover (Shivdasani, 1993; Beatty, 1995). From this standpoint, management uses employee ownership to put shares of the company in "friendly hands" (Benartzi et al., 2007). The argument is that collusion between management and employee owners is natural. Pagano and Volpin (2005) states that: "managers and workers are natural allies against takeover threats" (p. 841). From the employees' viewpoint, takeovers and subsequent mergers are often associated with layoffs. Employee ownership gives employees a voice to prevent these layoffs. Faleye et al. (2006) show that "labor uses its corporate governance voice to maximize the combined value of its contractual and residual claims, and that this often pushes corporate policies away from, rather than toward, shareholder value maximization" (p. 489). Gordon and Pound (1990) argue that many employee ownership plans were established in the US during the late 1980s explicitly to defend against takeovers. When an employee stock ownership plan is implemented, event studies report negative reactions of financial markets, in line with the management entrenchment hypothesis (Chang, 1990; Chang and Mayers, 1992; Conte et al., 1996). As a takeover defense, employee ownership may be even more powerful than poison pills or golden parachutes (Chaplinsky and Niehaus, 1994). Poison pills and golden parachutes are used less frequently when employee stock ownership plans are implemented (Park and Song, 1995). Rauh (2006) confirms that employee ownership has a deterrence effect on takeover probabilities. He further claims that: "Strategic corporate control motives are, therefore, one significant reason managers encourage employees to hold company stock in their defined contribution pension accounts." Brown et al. (2006) find that offering of match- 
ing contribution of company stock in $401(\mathrm{k})$ plans is more likely when companies do not have multiple classes of stock, which is an alternative mechanism to reduce takeover threats. According to Brown et al. (2006), employee ownership can then be interpreted as a tool to place shares in friendly hands to thwart takeovers.

According to the literature, employee ownership thus has two sides: a bright side involving enhanced corporate performance and a dark side leading to management entrenchment. These arguments can both be regarded as representing the motives of management to stimulate employee ownership. In several countries such as the US, management encourages employee ownership through matching contributions in company stock or a discount on the stock price. The level of employee ownership is the consequence of either restricting employers' matching contribution to company stock in 401(k) plans or offering discounts on company stock through employee stock purchase plans. In both cases, the level of employee ownership is left to the discretion of management. After the collapse of Enron in the 2000s, financial economists began to investigate empirically why employees had invested a large proportion of their wealth in their company stock, thereby neglecting basic diversification principles. Some economists underline that management policy triggered employees' overinvestment in the company. Benartzi (2001) finds that: "when the employer's contributions are automatically directed to company stock, employees invest more of their own contributions in company stock (p. 1748)". Purcell (2003) confirms this effect using archival data by emphasizing that 401(k) concentration in company stock is significantly higher in companies where matching contributions are offered in company stock. Our paper investigates the motives of management in providing matching contributions. Whereas Benartzi offers a behavioral explanation relying on employees' responses, we propose an explanation by taking into account management's motives. From our standpoint, this alternative explanation relies on asymmetric information. We suggest that managers reveal their management type through their employee ownership policy.

\section{The model}

Consider a model with three stages involving a risk-neutral manager and a riskaverse employee. In this game, the manager's wealth is fully invested in company stock but his stake does not allow him to ward off a takeover attempt. We assume the manager holds a given amount of company stock at the beginning of the game. These features allow us to analyze the game without explicitly including the other shareholders as players. The employee is representative of all company employees. The sequence of events, illustrated in Figure 1, comprises three stages. 


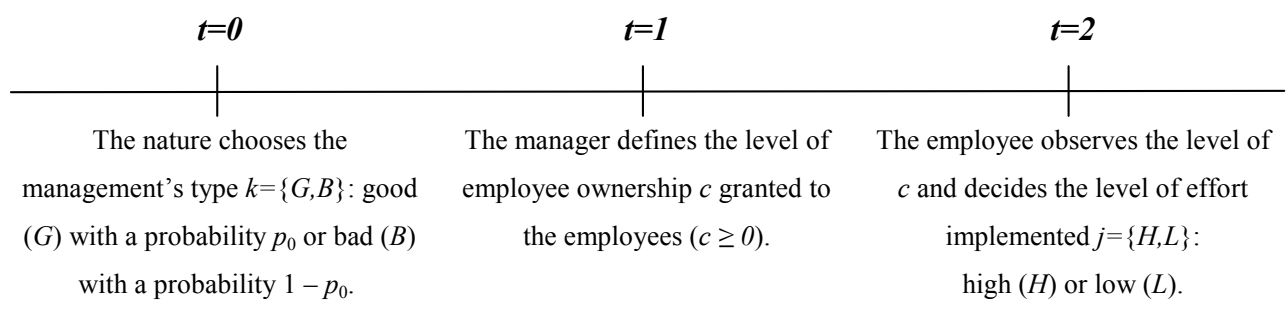

Figure 1: Timeline.

At $t=0$, the manager's type is chosen. There are two types of managers, i.e., good managers and bad managers, whose identities are only known by them. The manager's type can either be good $(\mathrm{G})$ or bad (B) with $k=\{G, B\}$. The employee does not observe the manager's type and she has an a priori probability distribution $P_{0}$ with regard to perception of the manager's type. Thus, $P_{0}(\mathrm{G})=p_{0}$ is the probability that the manager is good and $P_{0}(\mathrm{~B})=1-p_{0}$ is the probability that the manager is bad with $0<p_{0}<1$. The manager's type affects the rate of return on the company stock.

At $t=1$, the manager designs a compensation system aimed at motivating the employee to expand his level of effort. The compensation system we investigate only consists of company stock. $c$ is the level of employee ownership. We thus consider a setup where the manager has to decide whether to offer company stock to his employee and what amount of company stock to offer.

At $t=2$, the employee evaluates the compensation system and chooses the level of effort. The employee's effort can either be high (H) or low (L) with $j=\{H, L\}$. The level of effort affects the rate of return on the company stock.

The rate of return on the company stock is given by $r+\mu^{j, k}$ where $r$, which is a random variable with a mean of 0 , the volatility $\sigma$ and the density $f(r)$ represent the stochastic part of the rate of return and $\mu^{j, k}$ is the mean return of the company and takes different values according to manager's type $k$ and employee's effort $j . r$ and $\mu^{j, k}$ are independent random variables. The possible values of $\mu^{j, k}$ are: $\mu^{L, B}=$ $\mu ; \mu^{L, G}=\mu+\alpha ; \mu^{H, B}=\mu+\beta ; \mu^{H, G}=\mu+\alpha+\beta$. We then consider the three positive parameters $\mu, \alpha$ and $\beta$. $\mu$ is the mean return without effort and a bad manager, $\alpha$ measures how the manager's type affects the mean return and $\beta$ measures how the employee's effort affects the mean return. Ceteris paribus, it follows that a better manager or higher employee effort increases the rate of return on the company stock. The risk-neutral manager's expected utility is $V^{i, j, k}$ where $i$ denotes the level of company stock $c$ with $i=0, c$. The manager seeks to maximize the expected value of his wealth. The manager's initial wealth $W_{d}$ is positive and totally invested in company stock ${ }^{6}$. When the manager offers employee ownership, it takes the form of a contribution in company stock denoted by $c$. We suppose $c$ to be a proportion of $W_{s}$, which is the positive initial employee's wealth. Although the manager cannot directly observe his employees' wealth, he observes many employee' characteristics that are correlated to the overall wealth such as his age, his gender, his tenure, his rank, his education level, his fixed wage and bonus. Altogether, these variables make

\footnotetext{
${ }^{6}$ The introduction of a fixed salary does not modify the conclusions of the model.
} 
it possible to commensurate the employee ownership policy to the employees' wealth. $c W_{s}$ is therefore the monetary value of company stock granted to the employee that diminishes the manager's initial wealth $W_{d}$. Indeed, the monetary value of the contribution granted to the employee is often commensurate with the amount invested by the employee. For instance, it takes the form of a discount or a matching contribution. Degeorge et al. (2004) confirmed empirically that wealthier employees are more willing to take a firm exposure. If the manager grants the contribution in company stock, the manager's expected wealth is given by equation 2; otherwise, the manager expected wealth is given by equation 1 .

$$
\begin{gathered}
V^{0, j, k}=\int_{-\infty}^{+\infty} W_{d}\left(1+r+\mu^{j, k}\right) f(r) d r \\
V^{c, j, k}=\int_{-\infty}^{+\infty}\left(W_{d}-c W_{s}\right)\left(1+r+\mu^{j, k}\right) f(r) d(r)=\left(W_{d}-c W_{s}\right)\left(1+\mu^{j, k}\right)
\end{gathered}
$$

The risk-averse employee's expected utility is considered to be additively separable between the gains and the disutility of effort. The positive employee's initial wealth $W_{s}$ is totally invested in a risk-free asset whose rate of return is $r_{0}$. The effort $e$ is costly to the employee who endures $\psi(e)$, the disutility that is increasing with effort. If company stock is granted, the initial employee's wealth $W_{s}$ increases by an amount $c W_{s}$. If the employee receives $c W_{s}$, his expected utility is given by equation 4; otherwise, it is given by equation 3 .

$$
\begin{gathered}
U^{0, j}=u\left[W_{s}\left(1+r_{0}\right)\right]-\psi\left(e^{j}\right) \\
U^{c, j}=\int_{-\infty}^{+\infty}\left[p_{0} u\left[W_{s}\left(1+r_{0}\right)+c W_{s}\left(1+r+\mu^{j, G}\right)\right]\right. \\
\left.+\left(1-p_{0}\right) u\left[W_{s}\left(1+r_{0}\right)+c W_{s}\left(1+r+\mu^{j, B}\right)\right]\right] f(r) d r-\psi\left(e^{j}\right)
\end{gathered}
$$

where $u($.$) is a risk-averse von Neumann-Morgenstern utility function.$

We make the following assumptions with regard to the parameters:

Assumption 1: The employee is risk-averse and cautious (Gollier, 2008).

$$
\forall x: u^{\prime}(x)>0, u^{\prime \prime}(x)<0, \operatorname{RRA}(x)=-x \frac{u^{\prime \prime}(x)}{u^{\prime}(x)} \leq 1
$$

This hypothesis implies $\forall x,\left[x u^{\prime}(x)\right]^{\prime} \geq 0$

Assumption 2: The employee's expected utility is strictly positive when company stock is not granted and effort is low:

$$
U^{0, L}=u\left[W_{s}\left(1+r_{0}\right)\right]-\psi\left(e^{L}\right)>0
$$


Assumption 3: The employee's expected utility is higher with employee ownership for a given level of effort:

$$
\begin{aligned}
U^{c, j} & =\int_{-\infty}^{+\infty}\left[p_{0} u\left[W_{s}\left(1+r_{0}\right)+c W_{s}\left(1+r+\mu^{j, G}\right)\right]\right. \\
& \left.+\left(1-p_{0}\right) u\left[W_{s}\left(1+r_{0}\right)+c W_{s}\left(1+r+\mu^{j, B}\right)\right]\right] f(r) d r-\psi\left(e^{j}\right) \\
& \geq U^{0, j}=u\left[W_{s}\left(1+r_{0}\right)\right]-\psi\left(e^{j}\right), \forall c>0, \forall j=\{H, L\}
\end{aligned}
$$

\section{Employee ownership contracts}

In this section, we derive the solutions of the model and present circumstances in which employee ownership is used as an entrenchment tool or as a reward mechanism. We follow three steps. The first step describes the baseline contract, i.e., the employee ownership contract when there is no threat of dismissal for the manager. The second step introduces the threat of the dismissal for the manager. The third step investigates the managers' behavior.

\subsection{Employee ownership without threat of manager dismissal}

We solve for the equilibrium without dismissal threat. In the next sub-section, this threat takes the form of a minimum constraint on the company's return. Here, the manager does not have to reach a minimum level of return.

We define $\omega(c)$ as the difference between the employee's utility of wealth when a high level of effort is exerted and the utility of wealth resulting from a low level of effort.

$$
\begin{aligned}
\omega(c) & =\int_{-\infty}^{+\infty}\left[p_{0} u\left[W_{s}\left(1+r_{0}\right)+c W_{s}\left(1+r+\mu^{H, G}\right)\right]\right. \\
& \left.+\left(1-p_{0}\right) u\left[W_{s}\left(1+r_{0}\right)+c W_{s}\left(1+r+\mu^{H, B}\right)\right]\right] f(r) d r \\
& -\int_{-\infty}^{+\infty}\left[p_{0} u\left[W_{s}\left(1+r_{0}\right)+c W_{s}\left(1+r+\mu^{L, G}\right)\right]\right. \\
& \left.+\left(1-p_{0}\right) u\left[W_{s}\left(1+r_{0}\right)+c W_{s}\left(1+r+\mu^{L, B}\right)\right]\right] f(r) d r
\end{aligned}
$$

The employee chooses the high level of effort if this difference is higher than the supplementary disutility of effort $\psi\left(e^{H}\right)-\psi\left(e^{L}\right)$ needed to reach this level of effort. Lemma 1 describes the properties of $\omega(c)$ that allow the derivation of the solutions in the following section.

LEMma 1: The difference between the employee's utilities of wealth with high and low levels of effort defined by $\omega(c)$ has the following properties: $\omega(0)=0$ and $\omega^{\prime}(c)>0$. 


\section{Proof of Lemma 1: See the Appendix.}

Equilibrium is obtained if the manager grants a positive amount of company stock and if the employee exerts a high level of effort. Although other solutions may be investigated, we focus on the situation where employee exerts a high level of effort in the presence of a positive level of employee ownership. We thus illustrate the manager's strategies looking at a situation that is the most commonly identified by the literature on employee ownership. This situation describes a perfect subgame Nash equilibrium where manager's and employee's utilities are, respectively, $V^{c^{*}, H}$ and $U^{c^{*}, H}$, where $c^{*}$ is the equilibrium contribution in company stock. $\overline{c_{k}}$ is given by the manager's participation condition $V^{c, H, k} \geq V^{0, L, k} . \overline{c_{k}}$ represents the maximum compensation that can be granted by the manager. Above $\overline{c_{k}}$, employee ownership becomes too costly for the manager with $\overline{c_{k}}=\frac{W_{d}}{W_{s}} \frac{\mu^{H, k}-\mu^{L, k}}{1+\mu^{H, k}}$. The two threshold constraints $\overline{c_{G}}$ and $\overline{c_{B}}$ differ according to the two types of managers who know their type, which cannot be observed by the employee. Indeed, $\overline{c_{G}} \leq \overline{c_{B}}$. We thus state the following proposition.

Proposition 1 (Employee ownership contract without threat of manager dismissal): Under assumptions 1 to 3 , for $\omega^{-1}\left[\psi\left(e^{H}\right)-\psi\left(e^{L}\right)\right] \leq \overline{c_{G}}$, there exists a unique $c^{e}=c^{*} \in\left(0, \overline{c_{G}}\right]$, which is the perfect subgame Nash equilibrium. With $c^{e}$, the employee expends a high level of effort $(j=H)$ regardless of the manager's type. $c^{*}$ is given by the following relationship: $\omega\left(c^{*}\right)=\psi\left(e^{H}\right)-\psi\left(e^{L}\right)$.

Proof of Proposition 1: See the Appendix.

Figure 2 (see the Appendix) illustrates Proposition 1. The manager selects the minimum level of $c$ that insures a high level of effort at the intersection of $\omega(c)$ and $\psi\left(e^{H}\right)-\psi\left(e^{L}\right)$. Indeed, a higher amount of company stock granted is associated with deceased wealth for the entrepreneur's wealth, i.e. $V^{c, i, j}$. The additional disutility borne by the employee because of higher effort is exactly compensated by a supplementary utility of wealth. Figure 2 shows that the difference between the two levels of disutility of effort cannot be compensated above $\overline{c_{k}}$. Beyond $\overline{c_{k}}$, employee ownership becomes too costly to the manager.

\subsection{Employee ownership with threat of manager dismissal}

Now, we introduce a dismissal threat with the condition of a minimum performance level for the manager. In fact, poor performance may result in the removal of top executives. The minimum performance condition is noted as $V_{m}$ with $V_{m}>0$. If the manager's wealth $V^{c, i, j}$ is lower than $V_{m}$, the manager is dismissed ${ }^{7}$. Because the manager's wealth is fully invested in company stock, this condition corresponds to a minimum expected return on company stock exogeneously given by the shareholders. This constraint is consistent with Tirole (2006), who mentions that "there is a fair amount of evidence that executive turnover in the US is correlated with

\footnotetext{
${ }^{7}$ The employee can observe the minimum performance condition on the financial market. In the empirical section, we suggest that the company's risk adjusted performance can be compared to the risk adjusted performance of the sector the company belongs to.
} 
poor performance" (p. 25). Because of this minimum return condition, the manager can now lose his job. He can, however, prevent the dismissal if employee ownership is sufficiently high. The proportion of $W_{s}$ that guarantees the manager cannot be dismissed is $c_{m}$ and $c_{m} W_{s}$ is the monetary value of company stock granted to the employee. Therefore, the manager keeps his job if $c$ is higher than $c_{m}$. Because the manager cannot give the employee more than what he owns, $c_{m} W_{s}$ is lower than $W_{d}$.

The employee's optimal decision is to exert high effort in all cases according to Proposition 1. We distinguish three cases depending on the value of the manager's expected wealth relative to the constraint $V_{m}$ :

(i) No entrenchment: If the expected wealth of good and bad managers is higher than the constraint, i.e., if $V^{c^{*}, H, G}>V^{c^{*}, H, B} \geq V_{m}$, then both managers grant the same amount of company stock. The equilibrium contribution is $c^{*}$. In this case, employee ownership is not used as an entrenchment mechanism because the two types of manager both satisfy the minimum performance condition.

(ii) Good and bad manager entrenchment: If the expected wealth of good and bad managers is lower than the constraint, i.e., if $V_{m}>V^{c^{*}, H, G}>V^{c^{*}, H, B}$, then both managers select the higher contribution between $c_{m}$ and $c^{*}$. In this case, employee ownership is used as an entrenchment mechanism by both types of manager because they are not able to satisfy the minimum performance condition.

(iii) Bad manager entrenchment: If the value of the constraint is between the expected wealth of good managers and that of bad managers, i.e., if $V^{c^{*}, H, G} \geq V_{m}>$ $V^{c^{*}, H, B}$, then good and bad managers reveal their type. This last case corresponds to a separating equilibrium. Good managers play $c^{*}$, whereas bad managers select the higher contribution between $c_{m}$ and $c^{*}$. Indeed, picking $c_{m}$ allows bad managers to keep their job. In this case, employee ownership is only used as an entrenchment mechanism by the bad manager because she does not satisfy the minimum performance condition.

REMARK 1: We have an increase of $c$ for a given level of effort $(H)$. If $c^{*}>c_{m}$, both managers choose to play $c^{*}$. If $c^{*} \leq c_{m}$, managers reveal their type. Bad managers play $c_{m}$ and good managers play $c^{*}$.

In the sequel, we need an additional assumption to investigate the specific case where the manager's type is revealed. This assumption corresponds to the bad manager entrenchment case (iii).

Assumption 4: $V^{c^{*}, H, G} \geq V_{m}>V^{c^{*}, H, B}$, with $c^{*}$ as defined in Proposition 1.

The employee observes the manager's decision. His expected utility still depends on his level of effort but he now definitely knows the manager's type. He adapts his beliefs and his behavior, and his expected utility is given by equation 9 . 


$$
U^{c, j, k}=\int_{-\infty}^{+\infty} u\left[W_{s}\left(1+r_{0}\right)+c W_{s}\left(1+r+\mu^{j, k}\right)\right] f(r) d r-\psi\left(e^{j}\right)
$$

The relationship $\omega($.$) becomes \omega_{k}(c)=U^{c, H, k}-U^{c, L, k}$ because the employee is now able to identify the manager's type.

LEMMA 2: $\omega_{k}(c)$ has the following properties: $\omega_{k}(0)=0$ and $\omega_{k}^{\prime}(c)>0$. The solutions $c_{k}^{*}$, for $k=\{G, B\}$, of the equation $\omega_{k}\left(c_{k}^{*}\right)=\psi\left(e^{H}\right)-\psi\left(e^{L}\right)$ is such that $c_{B}^{*}<c^{*}<c_{G}^{*}$.

Proof of Lemma 2: See the Appendix.

REMARK 2: Irrespective of the $\overline{c_{k}}$ constraint, a higher amount is required from the good manager. Figure 3 in the appendix graphically illustrates lemma 2.

The equilibrium decision is now noted as $c_{k}^{e}$ in the sequel, where $k$ denotes the manager's type with $k=\{G, B\}$.

Proposition 2 (Employee ownership contracts according to the managers' type): Under assumptions 1 to 4 , for $\omega_{k}^{-1}\left[\psi\left(e^{H}\right)-\psi\left(e^{L}\right)\right] \leq \overline{c_{k}}$,

(i) If $c_{m}>c^{*}$, there exists a unique equilibrium contribution $c_{k}^{e}=c_{k}^{*}$ that induces a high level of effort $(j=H)$ depending on the manager's type $(k=\{G, B\}) \cdot \mathrm{c}_{k}^{e}$ satisfies the conditions of a perfect subgame Nash equilibrium and is defined as follows:

For the good manager $: c_{k}^{e}=\left\{\begin{array}{l}c_{G}^{*} \text { if }\left(W_{d}-c_{G}^{*} W_{s}\right)\left(1+\mu^{H, G}\right) \geq V_{m} \\ \operatorname{Max}\left(c_{G}^{*}, c_{m}\right) \text { if }\left(W_{d}-c_{G}^{*} W_{s}\right)\left(1+\mu^{H, G}\right)<V_{m}\end{array}\right.$

For the bad manager $: c_{k}^{e}=\left\{\begin{array}{l}c_{B}^{*} \text { if }\left(W_{d}-c_{B}^{*} W_{s}\right)\left(1+\mu^{H, B}\right) \geq V_{m} \\ c_{m} \text { if }\left(W_{d}-c_{B}^{*} W_{s}\right)\left(1+\mu^{H, B}\right)<V_{m}\end{array}\right.$

where $c_{G}^{*} \in\left(0, \overline{c_{G}}\right)$ and $c_{B}^{*} \in\left(0, \overline{c_{B}}\right)$ are given by the relationship $\omega_{k}\left(c_{k}^{*}\right)=\psi\left(e^{H}\right)-$ $\psi\left(e^{L}\right)$.

(ii) If $c_{m} \leq c^{*}$, there exists a unique $c^{e}=c^{*} \in\left(0, \overline{c_{G}}\right]$ that satisfies the conditions of a perfect subgame Nash equilibrium for $j=H$ and $k=\{G, B\}$. $c^{*}$ is given by $\omega\left(c^{*}\right)=\psi\left(e^{H}\right)-\psi\left(e^{L}\right)$.

Proof of Proposition 2: See the Appendix.

REMARK 3: The revelation of information increases the contribution for the good manager, and decreases the contribution for the bad manager for a given level of effort. These relationships hold when the constraint $\overline{c_{k}}$ and the revelation of the information have an effect. The bad manager offers a higher contribution to prevent a layoff. The level of the contribution increases because of the presence of the bad manager. This phenomenon can be analyzed as an adverse selection problem where signaling is costly to the good manager only because of the presence of the 
bad manager. Here, we underline that the good manager's wealth can now be below the $V_{m}$ constraint, i.e., the minimum performance condition. The managers must grant a higher level of employee ownership to signal their type. This higher level of employee ownership decreases the wealth of the managers. This conclusion does not contradict assumption 4; rather, it is the consequence of assumption 4 . According to this assumption 4, the good manager is not threatened because he always satisfies the minimum performance condition. Recall that the consequence of this new assumption is that the employee can perfectly identify the good and the bad managers. Indeed, the employee is always more demanding with the good manager. This situation occurs because the disutility of the effort difference does not depend on the manager's type. Furthermore, equilibrium is reached when this difference is equal to the expected difference in utility. This latter difference is higher for the good manager (see Figure 3), which is why the good manager's strategy is affected.

\subsection{Managerial behavior: cheating and commitment}

In this sub-section, we underline that the good and the bad manager have an incentive to cheat although their motivations are different: they can respectively offer the bad and the good contribution. In this situation, the equilibrium conditions no longer hold. This situation corresponds to the specific case where $c_{G}^{*}<c_{m}$ and $\left(W_{d}-c_{G}^{*} W_{s}\right)\left(1+\mu^{H, G}\right) \geq V_{m}>\left(W_{d}-c_{B}^{*} W_{s}\right)\left(1+\mu^{H, B}\right)$ (assumption 4 ).

We now present examples of strategies the two types of manager can implement. Recall that each type chooses to deviate if the other type does not deviate from its optimal strategy defined by proposition 2. The bad manager does not satisfy the minimum performance constraint $V_{m}$. The bad manager's strategy is therefore to appear good by giving $c_{G}^{*}$. He obtains a greater expected profit if he offers the good manager's contribution level $c_{G}^{*}$ rather than $c_{m}$ (see Proposition 2) because $c_{G}^{*}$ is lower than $c_{m}$. The good manager satisfies the minimum performance constraint $V_{m}$ and this situation incentivizes him to cheat. Indeed, the good manager obtains a greater expected profit if he offers the bad manager's contribution level $c_{B}^{*}$ rather than the good manager's contribution level $c_{G}^{*}$ (see Proposition 2) because $c_{B}^{*}$ is lower than $c_{G}^{*}$.

Furthermore, the good manager can still deviate from offering $c_{G}^{*}$ when $c_{G}^{*}>c_{m}$. In this latter case, maximizing his wealth leads him to reduce the amount of the contribution granted to the employee. He plays $c_{m}$ or $c_{B}^{*}$ rather than $c_{G}^{*}$. In all these cases, the good manager pays a lower contribution without being threatened with dismissal because he complies with the minimum performance condition $V_{m}$.

Therefore, it clearly appears that in this case $\left(c_{G}^{*}<c_{m}\right.$ and $\left(W_{d}-c_{G}^{*} W_{s}\right)\left(1+\mu^{H, G}\right) \geq$ $\left.V_{m}>\left(W_{d}-c_{B}^{*} W_{s}\right)\left(1+\mu^{H, B}\right)\right)$, good managers and bad managers can deviate from the strategies defined in proposition 2. Both managers have an incentive to cheat and the revelation is no longer possible. Moreover, the cheating of only one manager irrespective of his type is sufficient to prevent a separation from occurring. Indeed, the cheating of one player is optimal if the other does not cheat. This result leads to a second-round problem. There is an infinite regression phenomenon because each player is trying to infer the type or the behavior of the other. In this situation, no 
solution is derived and there is no optimal decision if cheating is possible.

Another way to solve the problem is to introduce commitments. The level of $c$ can be set before the nature chooses the manager's type. His expected value is then:

$$
\begin{aligned}
V^{0, j} & =p_{0} W_{d}\left(1+\mu^{j, G}\right)+\left(1-p_{0}\right) W_{d}\left(1+\mu^{j, B}\right) \\
& =W_{d}\left[1+p_{0} \mu^{j, G}+\left(1-p_{0}\right) \mu^{j, B}\right]
\end{aligned}
$$

or:

$$
\begin{aligned}
V^{c, j} & =p_{0}\left(W_{d}-c W_{s}\right)\left(1+\mu^{j, G}\right)+\left(1-p_{0}\right)\left(W_{d}-c W_{s}\right)\left(1+\mu^{j, B}\right) \\
& =\left(W_{d}-c W_{s}\right)\left[1+p_{0} \mu^{j, G}+\left(1-p_{0}\right) \mu^{j, B}\right]
\end{aligned}
$$

Proposition 3 (Employee ownership contract with prior commitment): Under assumptions 1 to 4 , for $\omega_{k}^{-1}\left[\psi\left(e^{H}\right)-\psi\left(e^{L}\right)\right] \leq \overline{c_{k}}$, there exists a unique $c_{k}^{e}$, which is the perfect subgame Nash equilibrium, for $j=H$ and $k=G, B$, such that:

- In the case where $c_{m}>c^{*}$,

(i) If $p_{0}\left(W_{d}-c^{*} W_{s}\right)\left(1+\mu^{H, G}\right) \geq\left(W_{d}-c_{m} W_{s}\right)(1+\bar{\mu}), c_{k}^{e}=c^{*}$,

(ii) If $p_{0}\left(W_{d}-c^{*} W_{s}\right)\left(1+\mu^{H, G}\right)<\left(W_{d}-c_{m} W_{s}\right)(1+\bar{\mu}), c_{k}^{e}=c_{m}$,

- In the case where $c_{m} \leq c^{*}, c_{k}^{e}=c^{*}$.

$c^{*}$ is given by the following relationship: $\omega\left(c^{*}\right)=\psi\left(e^{H}\right)-\psi\left(e^{L}\right)$, and $\bar{c}=\frac{W_{d}}{W_{s}} \frac{\beta}{1+\bar{\mu}}, \bar{\mu}=$ $\mu+\beta+p_{0} \alpha$

Proof of Proposition 3: See the Appendix.

REMARK 4: According to Proposition 3, a better compensation policy involving employee ownership should be designed before the manager type is known. From a managerial perspective, this means that the stockholders in charge of hiring and controlling the manager should not leave decisions regarding employee ownership policy to the manager's discretion. Otherwise, our conclusions show that managers are likely to use employee ownership to compensate their type. However, if such a recommendation is implemented, employee ownership no longer allows the separation of good managers from bad managers. The prior commitment means that the manager should not interfere with the employees' compensation policy involving employee ownership. From a practical point of view, the commitment can for instance consist in delegating the definition of the employee ownership compensation policy to the compensation committee of the company. This would decrease the potentially opportunistic influence of the manager on employee ownership policy.

\section{Comparative statics}

To illustrate how relational contracts can be used, this section provides numerical results of the model. The calibration requires the specification of the distributions of company stock returns and the employee's utility function. We take 
the usual assumption of normality for the distribution and a negative exponential utility function. Given the conditions of the perfect Nash equilibrium in the sub-game expounded in section 4.2 by Proposition 2 and the form of the negative exponential utility function, the analytical solution of $c_{k}^{e}$ is given by $c_{k}^{e}=c_{k}^{*}$ : $\omega_{k}\left(c_{k}^{*}\right)=\psi\left(e^{H}\right)-\psi\left(e^{L}\right)$.

See the calculus with a negative exponential utility function in the appendix.

Comparative statics analysis makes it possible to emphasize several properties of the solution. Figure 4 (see the Appendix) displays the results of the simulations ${ }^{8}$.

Figure 4 (a) displays the positive relationship between $p_{0}$ and $c^{*}$. A higher probability of having a good manager is associated with a higher amount of company stock granted to the employee. In an economy where good managers are more numerous, the employees request a higher contribution in company stock according to remark 3. If $p_{0}=0, c^{e}=c_{B}^{*}$, and if $p_{0}=1, c^{e}=c_{G}^{*}$.

Figure $4(\mathrm{~b})$ shows the relationship between $\alpha$ and $c^{*}, c_{G}^{*}$ and $c_{B}^{*}$. The $\alpha$ parameter establishes the difference between good and bad managers. Although it has no effect on $c_{B}^{*}$, it increases the value of the contribution $c_{G}^{*}$. This result confirms and reinforces the previous conclusion of Figure 4 (a) and remark 3. As the difference between bad and good managers increases, the employees become more demanding and seek to capture a higher proportion of the company's wealth. In a situation where the employees believe that they face good managers, they ask for a higher amount of company stock.

Figure 4 (c) displays the positive relationship between $\mu$ and $c^{*}, c_{G}^{*}$ and $c_{B}^{*}$. The $\mu$ parameter is the mean return on the company stock. From this chart, in a more profitable firm, employees have a greater desire to be compensated with company stock. We also notice a higher difference between $c_{G}^{*}$ and $c^{*}$ than between $c_{B}^{*}$ and $c^{*}$. Thus, for a given level of $\mu$, the employees are more sensitive to the company's performance when the company is led by a good manager.

Figure $4(\mathrm{~d})$ displays the negative relationship between $\sigma$ and $c^{*}, c_{G}^{*}$ and $c_{B}^{*}$. The $\sigma$ parameter is the standard deviation of the company's returns. According to this figure, in a riskier firm, the employee has a lower desire to be compensated with company stock. We also find less of a difference between $c_{G}^{*}$ and $c^{*}$ than between $c_{B}^{*}$ and $c^{*}$ as in Figure $4(\mathrm{c})$.

In Figures 4 (c) and 4 (d), we cannot draw any conclusion from the relative positions of the lines $c^{*}, c_{G}^{*}$ and $c_{B}^{*}$. Although the distance between $c^{*}$ and $c_{G}^{*}$ is greater than that between $c^{*}$ and $c_{B}^{*}$, these differences are only determined by the value of the parameter $p_{0}$ used in the simulations (i.e., 0.2). Another value would have resulted in a different position on the chart. For instance, if $p_{0}=0.5$, the $c^{*}$ line lies exactly halfway between $c_{G}^{*}$ and $c_{B}^{*}$.

\footnotetext{
${ }^{8}$ Values of the parameters are: $\overline{c_{G}}=0.65 ; p_{0}=0.2 ; r_{0}=0.05 ; \mu=0.1 ; \sigma=7.5 ; W_{s}=0.5 ; W_{d}=5 ; a=0.6$; $\alpha=0.05 ; \beta=0.05$
} 
Figure 4 (e) displays the negative relationship between $\beta$ and $c^{*}, c_{G}^{*}$ and $c_{B}^{*}$. The $\beta$ parameter establishes the difference between a high and a low effort exerted by the employee. An increase of $\beta$ denotes an increase in the productivity of the effort. According to this graph, this parameter has the same negative effect on $c^{*}, c_{G}^{*}$ and $c_{B}^{*}$. In fact, the employee's effort does not depend on the manager's type; it remains the same regardless of the manager's type is. However, as the productivity of the effort increases, the amount of company stock diminishes. To obtain the same return associated with a high level of effort, the manager pays the employee less because the productivity increases.

Figure 4 (f) shows the negative relationship between $a$ and $c^{*}, c_{G}^{*}$ and $c_{B}^{*}$. The $a$ parameter is the employee's absolute risk aversion. This parameter has the same negative effect on $c^{*}, c_{G}^{*}$ and $c_{B}^{*}$ because the employee's risk aversion does not depend on the manager's type. As the employee's risk aversion increases, he becomes more reluctant to hold risky assets.

Figure $4(\mathrm{~g})$ shows the curvilinear relationship between $W_{s}$ and $c^{*}, c_{G}^{*}$ and $c_{B}^{*}$. The $W_{s}$ parameter measures the employee's wealth. Considering assumption 3 , two different effects can be distinguished: a wealth effect arising from the value of $W_{s}$ and a scale effect related to the value of $\mu^{j, k}$. The increasing part of the curve is produced by the wealth effect. As the employee's wealth increases the difference between $U^{c, H}$ and $U^{c, L}$ denoted by $\omega$ decreases, which results in an increase of $c^{*}$. The decreasing part of the curve is produced by the scale effect and is more difficult to explain because it results from the form of the utility function. In fact, the parameter $a$ affects the concavity of the utility function and then is relative to risk aversion and to the marginal utility of wealth.

\section{Empirical study}

In this subsection, we present an empirical study investigating how employee ownership affects management tenure that takes into account the two motives of employee ownership examined in the model (i.e. management entrenchment and reward management). On the one hand, Rauh (2006) and Brown et al. (2006) confirmed previous studies' results (see section 2) in which employee ownership deters hostile takeovers. This is usually the main objective of an entrenchment mechanism. On the other hand, employee ownership is often used for reward management purpose (Kruse et al. 2010 and 2012). Our empirical study takes into account these two motives examined in the theoretical model by studying the relationship between employee ownership and management tenure. The data cover all managers' tenure of companies listed on the French SBF 120 index from 1998 to 2011. Employee ownership is usually criticized because it would cause free riding problem. Free riding would be all the more severe in large corporations. Although our data covers only large corporations, experimental and empirical literature contradicts this argument (Putterman, 2006; Kruse et al, 2010). Guedri and Hollandts (2008) show that employee ownership affects positively corporate performance of a sample of large French listed corporations. We include variables measuring management tenure, employee 
ownership and control variables. France has an intermediary model of governance. We found different forms of governance, as the companies can choose to adopt a unitary or dual board (Aste, 1999). France is also widely open to foreign investors. Employee ownership has been encouraged for decades through tax incentives and legislation.

\subsection{Variable definitions}

Management tenure - We build our sample using the Insead OEE Data Services (IODS). This dataset reports all managers' turnovers and their motives occurring between 1998 and 2011. Tenure is the total number of months a manager has been in office from the time the position was assumed until the time the position was left. The nature of the turnover is essential to our empirical analysis. The IODS dataset reports seven management turnover motives: death, exceeding the statutory age, retirement, promotion (for instance a $\mathrm{CEO}$ who became secretary of state), change of corporate control, resignation or mandate not renewed. Our sample does not include turnover resulting from a change of corporate control. We exclude managers whose turnover motive was death or promotion because variables explaining the tenure of these managers do not have an economic nature and are not explained by our model. We also exclude temporary managers because of the very short period of time they spend in the company. We finally exclude managers who were still in position in 2011. We keep in the sample managers whose turnover motive was: resignation (68 cases), mandate not renewed, retirement and exceeding the statutory age.

Employee ownership - A continuous variable that measures the level of employee ownership as the average percentage of outstanding equity held by employees during the period the manager is in office.

Control variables - In addition to tenure, for each manager whose turnover occurred between 1998 and 2011, we measure the age and whether the manager is the founding manager or a member of the founding family. Age is the age of the manager at the time he obtains the position of manager. The potential period of time a manager can stay in office is shorter for an older manager. A dummy variable takes the value of 1 if the manager founded the company or is part of the founding family and 0 otherwise. The assumption here is that a founding manager is more likely to stay in the position longer. Furthermore, founding managers frequently hold a large part of the equity. Following other empirical works that regarded board duality as an entrenchment tool (see Elsayed, 2007), we introduce a duality variable that takes the value of 1 if the board is unitary and 0 otherwise. Following Parrino (1997), we introduce a variable called inside CEO to determine whether the CEO had a position inside the company before he became CEO. This dummy variable takes the value of 1 if the CEO held a position in the company before he became CEO and 0 otherwise. Our measure of management tenure can be interpreted in different ways. For example, it is possible that managers' tenure is positively correlated with managerial quality or skill. In particular, the performance of managers can be the 
consequence of the implementation of employee ownership to incentivize employees to work harder (reward management). Consequently, a longer tenure could denote either good management or bad management. We measure the relative performance of each manager included in our sample by computing the difference between the annualized daily stock returns on the company stock and those on the sectoral index the company belongs to divided by the difference between the annualized volatility of the company stock returns and that of the corresponding index. By construction, this variable takes into account stock prize variations because of the inclusion of overall market index. The data are provided by the European financial data institute (EUROFIDAI). Each observation of this variable is computed by evaluating the historical stock or index prices from the date the manager becomes a manager to the date he leaves. The stock return and index return are then determined over each manager's entire tenure. We thus control for the risk/return performance of a given manager relative to his competitors in the same sector. To control for the size of the company, we finally compute the natural logarithm of the average amount of sales for the period the manager is in office.

After removing extreme values, we obtain a dataset consisting of 95 observations corresponding to managers who left office between 1998 and 2011.

\subsection{Descriptive statistics}

Companies in our sample belong to nine different sectors: discretionary consumption (29 companies), energy (3), finance (14), industry (22), materials (6), healthcare (4), collective services (5), information technology (11) and telecom (1). Descriptive statistics are displayed in Table 1 . The average percentage of equity held by employees is relatively low at 1.7 percent. The average CEO's age is 51 years and they stayed in the position for 5 years on average ( 59 months). Eight managers founded the company or were part of the founding family. The correlation matrix (available upon request) does not show high correlations between exogenous variables. The correlation coefficient between employee ownership and risk-adjusted return is very low $(0.0753)$ and not statistically significant $(p . v a l u e=04682)$, which shows that the employee ownership policy implemented by the manager is not related to the risk-adjusted performance. A significant correlation between these two variables would reveal a potential endogeneity bias when evaluating the relationship between employee ownership and management tenure ${ }^{9}$.

\subsection{Regression results}

We ran OLS regressions with a heteroskedasticity correction. The regression coefficients are displayed in Table 2. The obtained coefficients show a positive and significant relationship between the percentage of equity controlled by the employees and the number of months the manager stays in position, with all other variables equal. Furthermore, the positive relationship between the relative risk return variable and management tenure clearly displays that good managers stay in their

\footnotetext{
${ }^{9}$ The correlation matrix is available from the authors upon request
} 
position longer. This result also shows that managers who demonstrate good performance do not leave to join other companies. This is not surprising because numerous incentive policies (especially compensation policies) are intended to make managers loyal to their company in cases of good performance. From a contextual point of view, our sample belongs to the SBF 120 index, which includes the largest companies in the French market. However, few French managers lead large companies abroad and vice versa. Consequently, in the case of good performance, managers do not have an incentive to leave their company ${ }^{10}$. Taken together, these two results (i.e., the positive relationship between employee ownership and management tenure on the one hand and relative risk return performance on the other hand) confirm the conclusion of the model according to which lower-performing managers use employee ownership as an entrenchment mechanism.

\section{Concluding remarks}

In this paper, we set up a model that regards employees compensation in company stock as an imperfect signal of management quality. This viewpoint significantly differs from the existing literature in behavioral finance, which assumes that employees invest their money in their firm because they consider their employer's contribution in company stock as implicit investment advice. However, employee ownership is often analyzed as an entrenchment mechanism in the corporate governance literature. The contributions of this paper are both theoretical and empirical. Our model presents three main conclusions. First, we show that employee ownership can be used by managers to compensate their actual management skills. This first result is consistent with Pagano and Volpin (2005), who argue that managers can protect their own control by setting up employee stock ownership plans. Second, we demonstrate that employees demand higher contributions in company stock to the good managers than to the bad managers. This situation is similar to an adverse selection problem where the presence of bad managers makes it costly for good managers to signal themselves. However, this phenomenon presents another problem because it incentivizes both types of managers to hide their actual type; it is valuable for the bad managers to appear to be good managers. Similarly, appearing to be a bad manager can also be profitable for good managers. To solve this problem, we introduce commitments, which leads us to our third main result, which has a normative thrust. To prevent managers from hiding their actual type, our model suggests that compensation mechanisms involving employee ownership should be defined before the manager's type is known. In other words, managers should not interfere with employee ownership policy. The comparative statics section highlights several main results. First, in a situation where employees believe that they face good managers, they ask for a higher amount of company stock. Second, for a given level of $\mu$, the employees are more sensitive to the company's performance when the company is led by a good manager. Third, as the productivity of the effort increases, the amount of company stock granted to the employee decreases.

\footnotetext{
${ }^{10}$ This result questions the use of management tenure as a measure of management entrenchment (see for instance Balkin et al. (2000) and Makri et al. (2006)). Indeed, long tenure reveals not only entrenchment but also good management.
} 
Finally, considering the two main motives of employee ownership examined by the model (i.e., reward management and management entrenchment), we determined a positive relationship between employee ownership and management tenure. This result provides new evidence that employee ownership can be used as an entrenchment mechanism. Additionally, this empirical conclusion could be moderated by certain limits. As a matter of fact, it can be argued that this conclusion is sensitive to the institutional context. Moreover, the model predicts that the signaling effect depends on the cost of employee ownership. However, high-performing managers can choose to signal themselves through other best practices. In contrast, poorly performing managers can use other, less costly means to stay in position, depending on each country's legislation. From an empirical point of view, further investigation is clearly needed to incorporate alternative entrenchment and signaling strategies.

\section{References}

Aste, L., 1999. Reforming French corporate governance: a return to the two-tier board?. The George Washington J. of Internat. Law and Econ. 32, 1-72.

Balkin, D., Markman, G., and Gomez-Mejia, L., 2000. Is CEO pay in high-technology firms related to innovation?. Acad. of Man. J. 43, 1118-1129.

Beatty, A. 1995. The cash flow and informational effects of ESOP. J. of Fin. Econ.. 38, 211-240.

Benartzi, S., 2001. Excessive extrapolation and the allocation of company stock to retirement accounts. J. of Fin. 56, 1747-1764.

Benartzi, S., Thaler, R., Utkus S., Sunstein C., 2007. The law and economics of company stock in 401(k) plans. J. of Law and Econ. 50, 45-79.

Blasi, J., 1988. Employee ownership: revolution or ripoff? Harper Busines ed., New York.

Brown J., Liang N., Weisbenner S., 2006. 401(k) matching contributions in company stock: costs and benefits for firms and workers. J. of Pub. Econ. 90, 1315-1346.

Buchko, A., 1992. Employee ownership, attitudes and turnover: an empirical assessment. Human Relations. 45, 711-733.

Buchko, A. 1993. The effects of employee ownership on employee attitudes: an integrated causal model and path analysis. J. of Manag. Stud. 30, 633-657.

Chang, S. 1990. ESOPs and shareholder wealth: an empirical investigation. Fin. Manag. 19, 48-58.

Chang, S., Mayers, D., 1992. Managerial vote ownership and shareholder wealth: evidence from ESOP. J. of Fin. Econ. 32, 103-131.

Chaplinsky, S., Niehaus, G., 1994. The role of ESOPs in takeover contests. J. of Fin. 49, 1451-1470.

Conte, M., Blasi, J., Kruse, D., Jampani, R., 1996. Financial returns of public ESOP companies: 
investors effecs vs. manager effects. Fin. Anal. J. 52, 51-61.

Elsayed, K., 2007. Does CEO duality really affect corporate performance?. Corp. Gov.: An Internat. Rev. 15, 1203-1214.

Faleye, O., Mehrotra, V., Morck, R., 2006. When labor has a voice in corporate governance. J. of Fin. and Quant. Anal. 41, 489-510.

French, J., 1987. Employee perspectives on stock ownership: financial investment or mechanism of control? Acad. of Manag. Rev. 12, 427-435.

Gamble, J., Culpepper, R., Blubaugh, M., 1999. ESOPs and employee attitudes: the importance of empowerment and financial value. Personnel Rev. 31, 9-26.

Gollier, C., 2008. Understanding saving and portfolio choices with predictable changes in assets returns. J. of Math. Econ. 44, 445-458.

Gordon, L., Pound, J., 1990. ESOPs and corporate control. J. of Fin. Econ. 27, 525-556.

Guedri, Z., Hollandts, X., 2008. Beyond dichotomy: The curvilinear impact of employee ownership on firm performance. Corporate Governance: An Int. Rev., 16, 460-474.

Holden, S., Van Derhei, J., 2001. 401(k) plan asset allocation, account balances, and loan activity in 2000. ICI Persp. 7, 1-27.

Klein, K. 1987. Employee stock ownership and employees attitudes: a test of three models. J. of Appl. Psy. 72, 319-332.

Kruse, D., 2002. Research evidence on prevalence and effects of employee ownership. Paper presented in testimony before the subcommittee on employee-employer relations, Committee on Education and Workforce, U. S. House of Representatives, Feb. 13.

Kruse, D., Blasi, J., 1997. Employee ownership, employee attitudes, and firm perfomance: a review of the evidence, in: Lewin, D., Mitchell, D., Zaidi, M. (Eds), The Human Resources Management Handbook, Part 1. JAI Press, Greenwich, pp. 113-151.

Kruse, D., Freeman, R., Blasi, J., 2010. Shared capitalism at work: employee ownership, profit and gain sharing, and broad-based stock options. The University of Chicago Press, Series: National Bureau of Economic Research Conference Report, Chicago.

Kruse, D., Blasi, J., Freeman, R., 2012. Does linking worker pay to firm performance helps the best firms to do even better? NBER working paper 17745 .

Makri, M., Lane, P., Gomez-Mejia, L., 2006. CEO incentives, innovation, and performance in technology-intensive firms : a reconciliation of outcome and behavior-based incentives schemes. Strat. Manag. J. 27, 1057-1080.

Pagano, M., Volpin, P. 2005. Workers, managers, and corporate control. J. of Fin. 60, 841-868.

Park, S., Song M. 1995. Employee stock ownership plans, firm performance and monitoring by outside blockholders. Fin. Manag. 24, 52-65.

Parrino, R., 1997. CEO turnover and tutside seccesion : a cross-sectional analysis. J. of Fin. Econ. 46, 165-197. 
Pendleton, A., Robinson, A., 2010. Employee stock ownership, involvement and productivity: an interaction-based approach. Ind. and Labor Rel. Rev. 64, 3-29.

Putterman L., 2006. Reciprocity, altruism and cooperative production, in Ythier J.-M., Kolm, S.-C. eds, Handbook of the economics of giving, altruism and reciprocity, Palgrave Macmillan.

Rauh, J., 2006. Own company stock in defined contribution pension plans: a takeover defense?. J. of Fin. Econ. 81, 379-410.

Rosen, C., Klein, K., Young, K., 1986. Employee ownership in America: the equity solution. Lexington books, Lexington.

Shivdasani, A. 1993. Board composition, ownership structure and hostile takeover. J. of Acc. and Econ. 16, 148-153.

Tirole, J. 2006. The theory of corporate finance. Princeton University Press, Princeton.

Weitzman, M., 1984. The share economy. Harvard University Press, Cambridge. 


\section{Appendix}

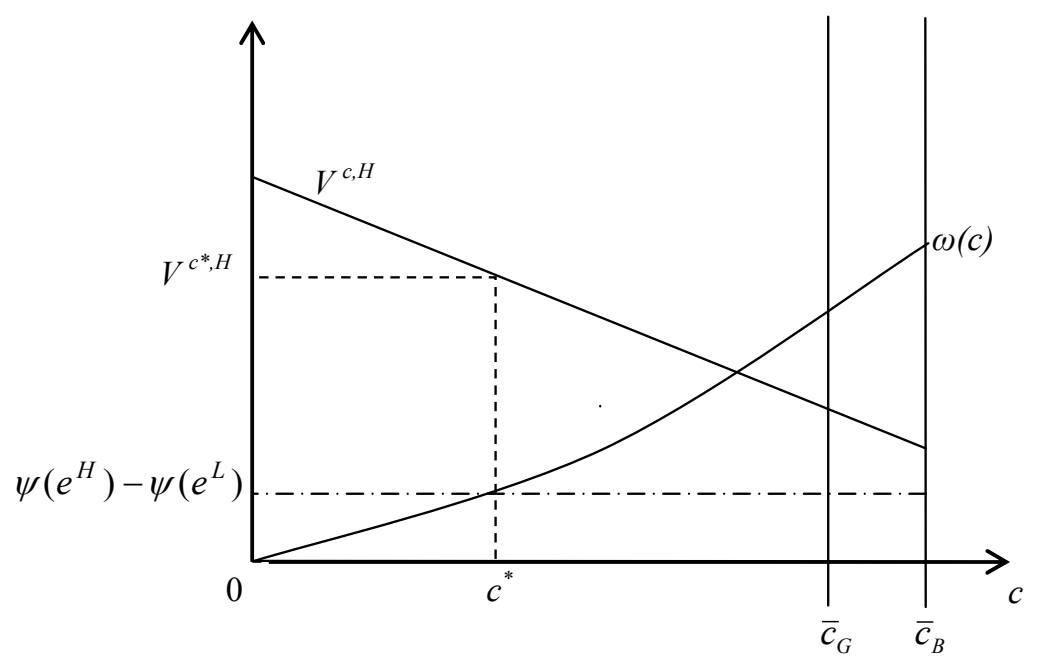

Figure 2: Employee ownership contract without dismissal threat.

Notes. Thick lines represent (i) entrepreneur's wealth $V^{c, H}$ with the optimal contract; (ii) the maximum thresholds of company stock granted $\overline{c_{k}}$; (iii) the difference of employee's utility wealth due to a high level of effort $\omega_{k}(c)$. Dash line represents the disutility of effort bore by the employee.

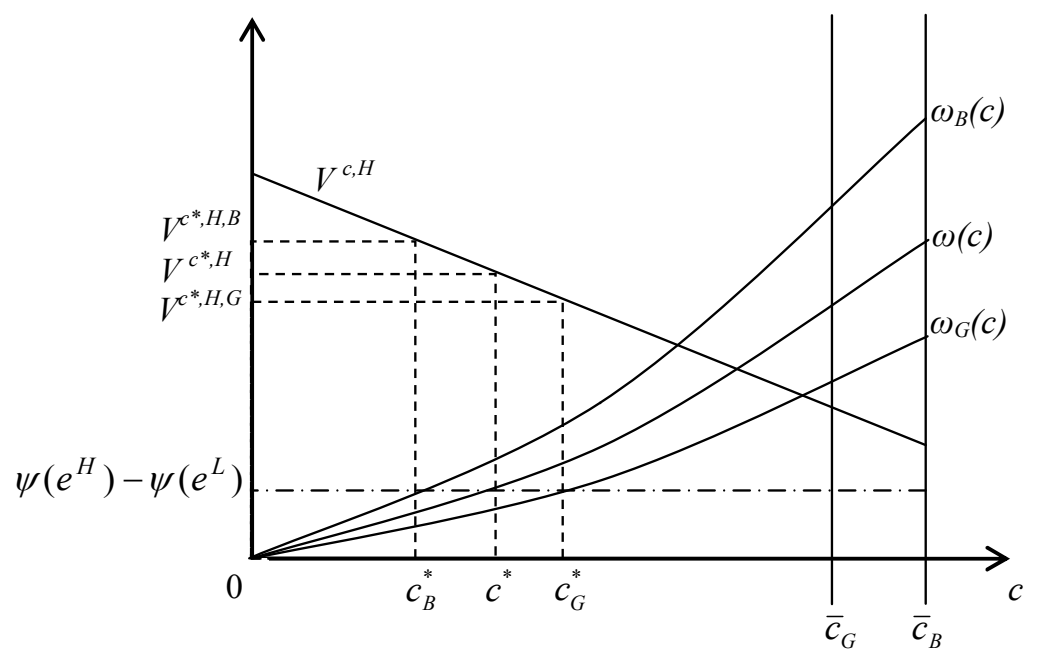

Figure 3: Employee ownership contract with dismissal threat.

Notes. Thick lines represent (i) entrepreneur's wealth $V^{c, H}$ with the optimal contract; (ii) the maximum thresholds of company stock granted $\overline{c_{G}}$ and $\overline{c_{B}}$; (iii) the difference of employee's utility wealth due to a high level of effort $\omega_{k}(c)$. Dash line represents the disutility of effort bore by the employee. 


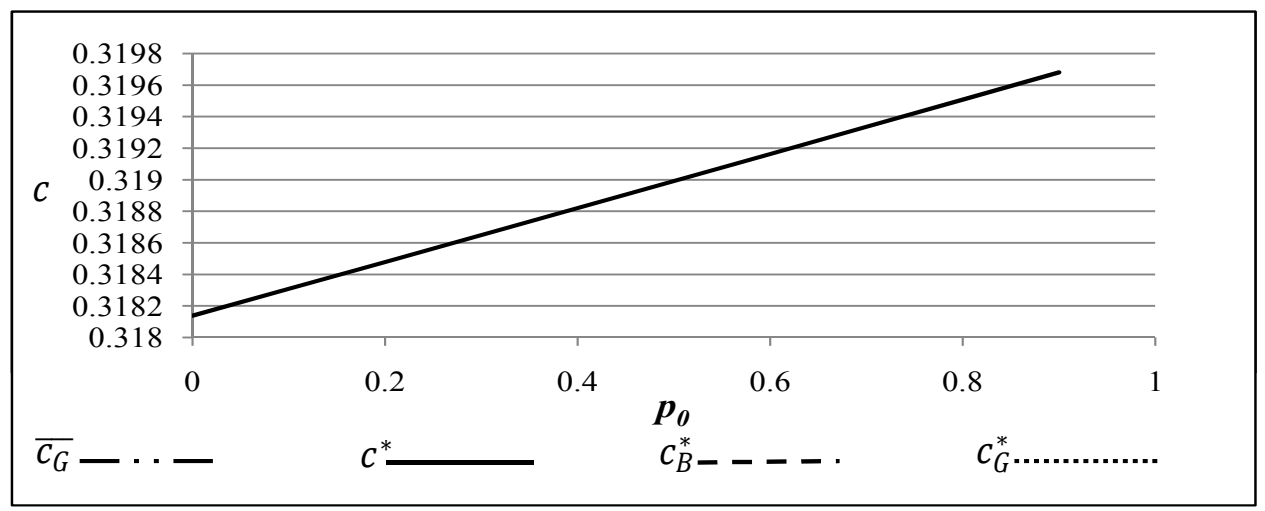

Figure 4(a) - Relationship between $p_{0}$ and $c^{*}$

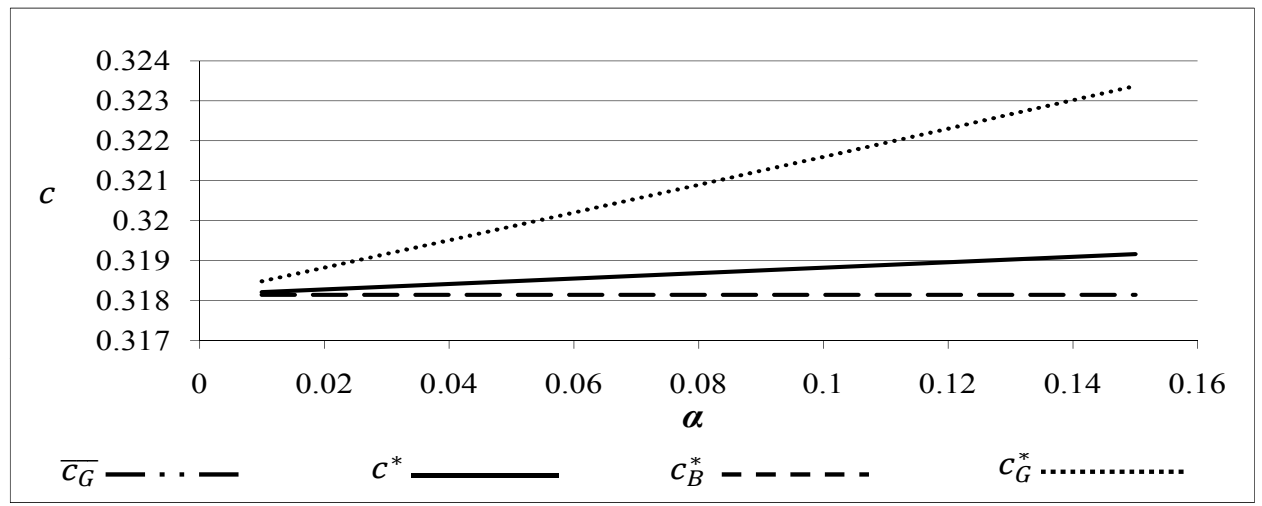

Figure 4(b) - Relationship between $\alpha$ and $c^{*}$

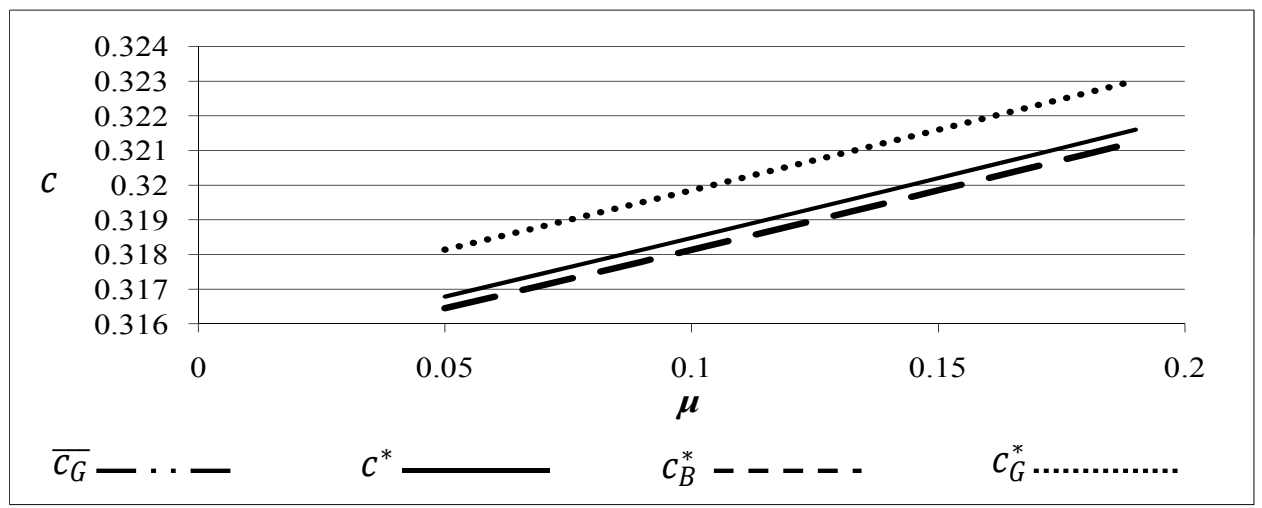

Figure 4(c) - Relationship between $\mu$ and $c^{*}$ 


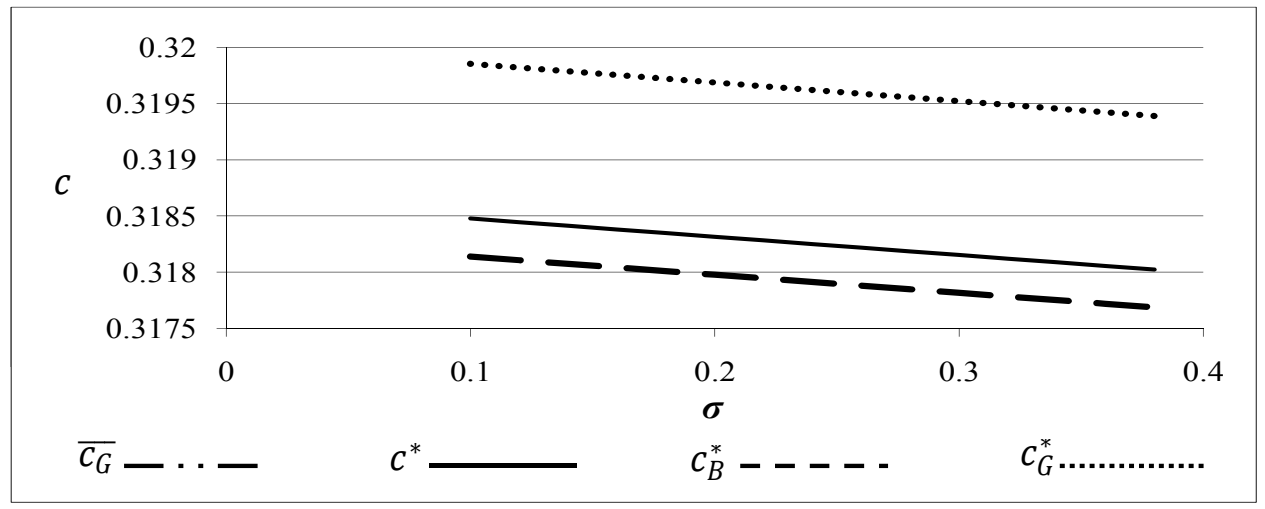

Figure 4(d) - Relationship between $\sigma$ and $c^{*}$

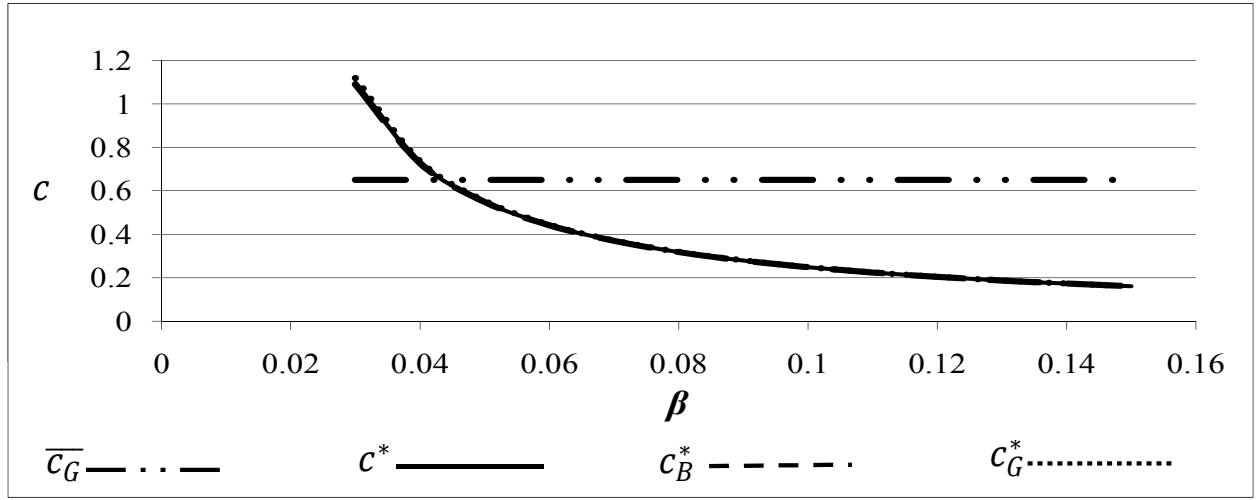

Figure 4(e) - Relationship between $\beta$ and $c^{*}$

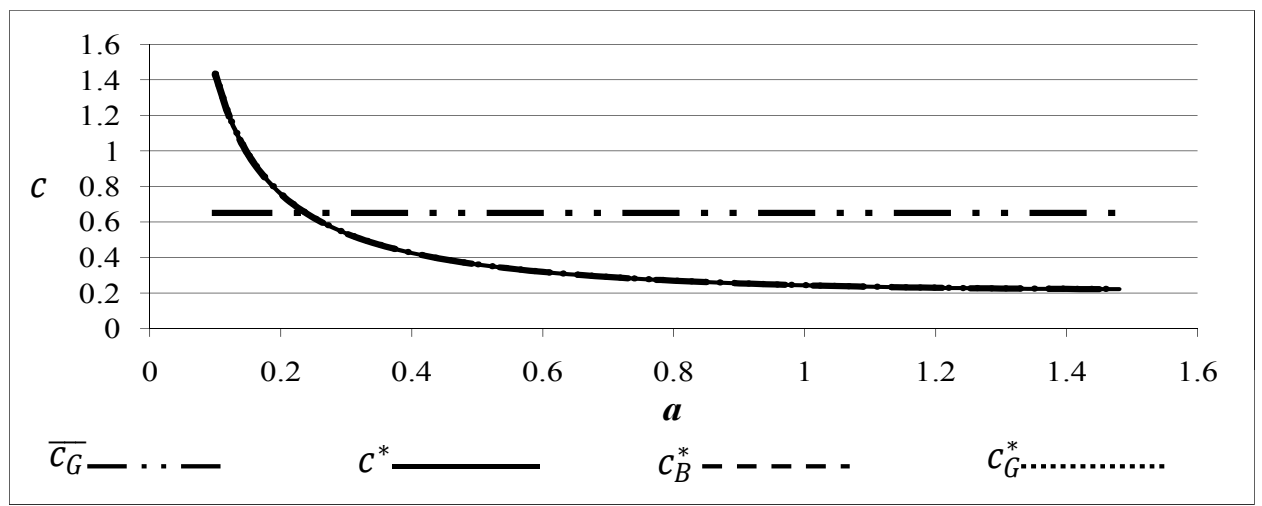

Figure 4(f) - Relationship between $a$ and $c^{*}$ 


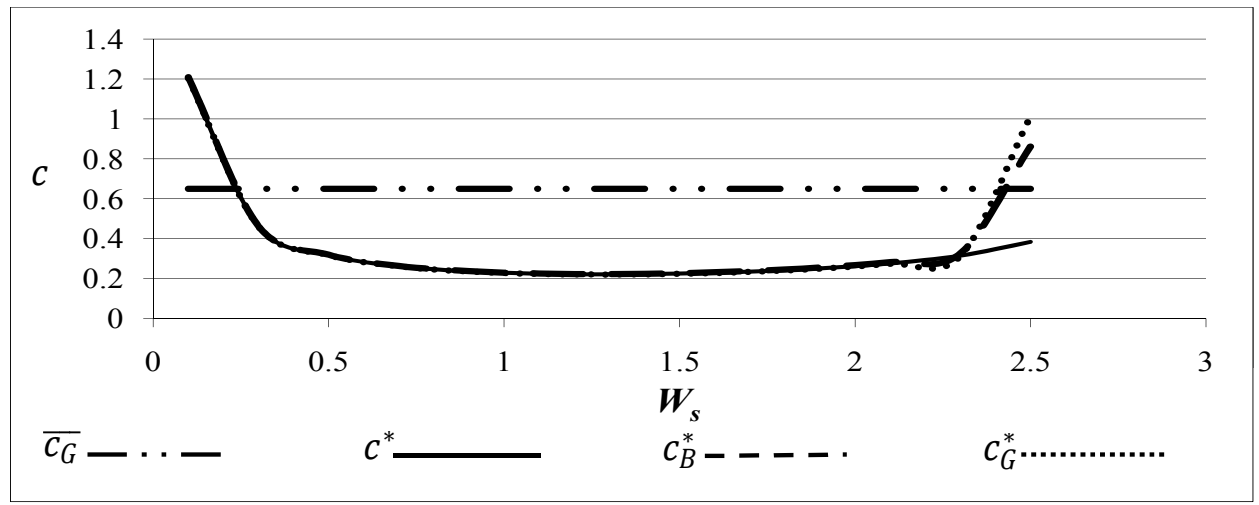

Figure 4(g) - Relationship between $W_{s}$ and $c^{*}$

\section{Proof of Lemma 1:}

Let $\omega(c)$ be defined by equation 8 and developed as follows:

$$
\begin{aligned}
\omega(c)= & \int_{-\infty}^{+\infty}\left[p _ { 0 } \left(u\left[W_{s}\left(1+r_{0}\right)+c W_{s}(1+r+\mu+\alpha+\beta)\right]\right.\right. \\
& \left.\left.-u\left[W_{s}\left(1+r_{0}\right)+c W_{s}(1+r+\mu+\alpha)\right]\right)\right] f(r) d r \\
& -\int_{-\infty}^{+\infty}\left[( 1 - p _ { 0 } ) \left(u\left[W_{s}\left(1+r_{0}\right)+c W_{s}(1+r+\mu+\beta)\right]\right.\right. \\
& \left.\left.-u\left[W_{s}\left(1+r_{0}\right)+c W_{s}(1+r+\mu)\right]\right)\right] f(r) d r
\end{aligned}
$$

We have first $\omega(0)=0$. For the second property:

$$
\begin{aligned}
\omega^{\prime}(c)= & \int_{-\infty}^{+\infty}\left[p _ { 0 } \left(W_{s}(1+r+\mu+\alpha+\beta) u^{\prime}\left[W_{s}\left(1+r_{0}\right)+c W_{s}(1+r+\mu+\alpha+\beta)\right]\right.\right. \\
& \left.-W_{s}(1+r+\mu+\alpha) u^{\prime}\left[W_{s}\left(1+r_{0}\right)+c W_{s}(1+r+\mu+\alpha)\right]\right) \\
& +\left(1-p_{0}\right)\left(W_{s}(1+r+\mu+\beta) u^{\prime}\left[W_{s}\left(1+r_{0}\right)+c W_{s}(1+r+\mu+\beta)\right]\right. \\
& \left.\left.-W_{s}(1+r+\mu) u^{\prime}\left[W_{s}\left(1+r_{0}\right)+c W_{s}(1+r+\mu)\right]\right)\right] f(r) d r
\end{aligned}
$$

$$
\text { Let } \begin{aligned}
X & =W_{s}\left(1+r_{0}\right)+c W_{s}(1+r+\mu+\alpha+\beta) \\
Y & =W_{s}\left(1+r_{0}\right)+c W_{s}(1+r+\mu+\alpha) \\
Z & =W_{s}(1+r+\mu+\beta) \\
T & =W_{s}(1+r+\mu)
\end{aligned}
$$

Replacing $X, Y, Z$, and $T$ in equation 17 :

$$
\begin{aligned}
\omega^{\prime}(c)= & \int_{-\infty}^{+\infty}\left[p_{0}\left[\frac{X-W_{s}\left(1+r_{0}\right)}{c} u^{\prime}(X)-\frac{Y-W_{s}\left(1+r_{0}\right)}{c} u^{\prime}(Y)\right]\right. \\
& \left.+\left(1-p_{0}\right)\left[\frac{Z-W_{s}\left(1+r_{0}\right)}{c} u^{\prime}(Z)-\frac{T-W_{s}\left(1+r_{0}\right)}{c} u^{\prime}(T)\right]\right] f(r) d r
\end{aligned}
$$




$$
\begin{aligned}
\omega^{\prime}(c)= & \frac{1}{c} \int_{-\infty}^{+\infty}\left[p_{0}\left[X u^{\prime}(X)-Y u^{\prime}(Y)\right]+\left(1-p_{0}\right)\left[Z u^{\prime}(Z)-T u^{\prime}(T)\right]\right. \\
& \left.+W_{s}\left(1+r_{0}\right)\left(p_{0}\left[u^{\prime}(Y)-u^{\prime}(X)\right]+\left(1-p_{0}\right)\left[u^{\prime}(T)-u^{\prime}(Z)\right]\right)\right]
\end{aligned}
$$

Under assumption 1, and with: $\forall r, X>Y$, and $Z>T$, we have:

$\forall r, u^{\prime}(Y)>u^{\prime}(X), u^{\prime}(T)>u^{\prime}(Z), X u^{\prime}(X)=Y u^{\prime}(Y), Z u^{\prime}(Z)=T u^{\prime}(T)$, and then $\omega^{\prime}(c)>0$.

\section{Proof of Proposition 1:}

A Perfect Subgame Nash Equilibrium $\left(V^{c, H}, U^{c, H}\right)$, with $c>0$, must satisfy the following conditions:

The manager plays $c>0$ if $V^{c, H} \geq V^{0, L}$ and $V^{c, H} \geq 0$.

The employee chooses the level of effort $k=H$ if $\stackrel{U^{c}, H}{ } \geq U^{c, L}$ and $U^{c, H} \geq 0$.

First, according to assumption 2, when $c=0$, the expected utility of employee is strictly positive with the level of effort $j=L$, and strictly greater than the value obtained with $j=H$, because $\psi\left(e^{H}\right)>\psi\left(e^{L}\right)>0$. Therefore, participation of the employee in the firm is optimal. Then, $U^{c, H}=U^{c, L}$ and $U^{c, L}=U^{0, L}$ (see assumption 3), implies $U^{c, H} \geq 0$.

Second, the manager's exit cannot be an equilibrium because, $V^{0, L}$ is always possible, as it is stated in the first point, and it is strictly positive. Then, $V^{c, H} \geq V^{0, L}$ implies $V^{c, H} \geq 0$.

Third, with $\omega\left(c^{*}\right)=\psi\left(e^{H}\right)-\psi\left(e^{L}\right)$, and the lemma 1, the condition $\omega^{-1}\left[\psi\left(e^{H}-\right.\right.$ $\left.\psi\left(e^{L}\right)\right] \leq \overline{c_{k}}, \forall k=G, B$ implies $c^{*} \leq \overline{c_{k}}$. $\overline{c_{k}}$ is the maximum compensation that can be granted by the manager. Above $\overline{c_{k}}$, employee ownership becomes too costly for the manager. Indeed, the manager grants company stock if $V^{c^{*}, H, k} \geq V^{0, L, k}$ which gives the value of $\overline{c_{k}}$ :

$$
\overline{c_{k}}=\frac{W_{d}}{W_{s}} \frac{\mu^{H, k}-\mu^{L, k}}{1+\mu^{H, k}}
$$

It follows that the participation condition of the manager $V^{c^{*}, H, k} \geq V^{0, L, k}$ for any $k$ necessitates $c^{*} \leq \overline{c_{k}}$.

Fourth, $U^{c, H} \geq U^{c, L}$ is equivalent to $\omega(c) \geq \psi\left(e^{H}\right)-\psi\left(e^{L}\right)$

This characterizes a Perfect Subgame Nash Equilibrium with a positive $c^{e}$, with an equality in the preceding relation.

\section{Proof of Lemma 2:}

The properties of the functions $\omega_{k}(c)$ result of a straightforward adaptation of the proof of Lemma 1.

$$
\begin{aligned}
\omega_{G}(c)= & \int_{-\infty}^{+\infty}\left[u\left[W_{s}\left(1+r_{0}\right)+c W_{s}(1+r+\mu+\alpha+\beta)\right]\right. \\
& \left.-u\left[W_{s}\left(1+r_{0}\right)+c W_{s}(1+r+\mu+\alpha)\right]\right] f(r) d r
\end{aligned}
$$




$$
\begin{aligned}
\omega_{B}(c)= & \int_{-\infty}^{+\infty}\left[u\left[W_{s}\left(1+r_{0}\right)+c W_{s}(1+r+\mu+\beta)\right]\right. \\
& \left.-u\left[W_{s}\left(1+r_{0}\right)+c W_{s}(1+r+\mu)\right]\right] f(r) d r
\end{aligned}
$$

$$
\begin{array}{ll} 
& X=W_{s}\left(1+r_{0}\right)+c W_{s}(1+r+\mu+\alpha+\beta) \\
\text { Let } \quad Y=W_{s}\left(1+r_{0}\right)+c W_{s}(1+r+\mu) \\
a=c W_{s} \alpha \\
\\
\omega_{G}(c)=\int_{-\infty}^{+\infty}[u(X+a)-u(Y+a)] f(r) d r \\
\omega_{B}(c)=\int_{-\infty}^{+\infty}[u(X)-u(Y)] f(r) d r
\end{array}
$$

with $X>Y$.

As $u($.$) is a strictly concave function, for any r$, and for any strictly positive $a$, $u(X+a)-u(Y+a)<u(X)-u(Y)$, and then, $\omega_{G}(c)<\omega_{B}(c)$, for any positive c.

With $\omega(c)=p_{0} \omega_{G}(c)+\left(1-p_{0}\right) \omega_{B}(c)$, and the preceding equation, we have $c_{B}^{*}<$ $c^{e}<c_{G}^{*}$.

\section{Proof of Proposition 2:}

First, when $c_{m} \leq c^{*}$, with the condition $\omega_{G}^{-1}\left[\psi\left(e^{H}-\psi\left(e^{L}\right)\right] \leq \overline{c_{G}}\right.$, the inequalities $\overline{c_{G}} \leq \overline{c_{B}}$ and $c_{B}^{*}<c^{*}<c_{G}^{*}$ (see Lemma 2), without revelation, the equilibrium is obtained like in Proposition 1.

Second, when $c_{m}>c^{*}, c_{G}^{*}$ and $c_{B}^{*}$ are defined as $c^{*}$ in Proposition 1 , with $\omega_{G}($. and $\omega_{B}($.$) instead of \omega($.$) . Their existence is satisfied with respect to Lemma 2$ and the inequalities stated in the first point.

For good managers : $c_{k}^{e}=\left\{\begin{array}{l}c_{G}^{*} \text { if }\left(W_{d}-c_{G}^{*} W_{s}\right)\left(1+\mu^{H, G}\right) \geq V_{m} \\ \operatorname{Max}\left(c_{G}^{*}, c_{m}\right) \text { if }\left(W_{d}-c_{G}^{*} W_{s}\right)\left(1+\mu^{H, G}\right)<V_{m}\end{array}\right.$

For bad managers $: c_{k}^{e}=\left\{\begin{array}{l}c_{B}^{*} \text { if }\left(W_{d}-c_{B}^{*} W_{s}\right)\left(1+\mu^{H, B}\right) \geq V_{m} \\ c_{m} \text { if }\left(W_{d}-c_{B}^{*} W_{s}\right)\left(1+\mu^{H, B}\right)<V_{m}\end{array}\right.$

\section{Proof of Proposition 3:}

First, the condition $V^{c, H} \geq V^{0, L}$ is now:

$$
c \leq \bar{c}=\frac{W_{d}}{W_{s}} \frac{p_{0}\left(\mu^{H, G}-\mu^{L, G}\right)+\left(1-p_{0}\right)\left(\mu^{H, B}-\mu^{L, B}\right)}{1+p_{0} \mu^{H, G}+\left(1-p_{0}\right) \mu^{H, B}}=\frac{W_{d}}{W_{s}} \frac{\beta}{1+\bar{\mu}}, \bar{\mu}=\mu+\beta+p_{0} \alpha
$$

Second, when $c_{m}>c^{*}$, for $c=c^{*}$, the expected value of the entrepreneur is: $V^{c^{*}, H}=p_{0}\left(W_{d}-c^{*} W_{s}\right)\left(1+\mu^{H, G}\right)$, and for $c=c_{m}$, the expected value of the entrepreneur is $V^{c_{m}, H}=\left(W_{d}-c_{m} W_{s}\right)(1+\bar{\mu})$, then, if $V^{c^{*}, H} \geq V^{c_{m}, H}$, the optimal choice is $c^{*}$, and if $V^{c^{*}, H}<V^{c_{m}, H}$ the optimal choice is $c_{m}$. 
Third, if $c_{m} \leq c^{*}$, the optimal choice is $c^{*}$.

These results are a direct adaptation of Propositions 1 and 2.

\section{Application with a negative exponential utility function}

This function is defined up to a positive linear transformation: $u(w)=\lambda v(w)+\epsilon$, and must satisfy the following normalization ${ }^{11}: u(0)=0$. Then, $\epsilon=\lambda$, and, without loss of generality, we take $\lambda=1$. Therefore, in the sequel, the utility is ${ }^{12}: u(w)=$ $1-e^{-a w}$.

Let:

$$
F^{j, k}(c)=\int_{-\infty}^{+\infty} u\left[W_{s}\left(1+r_{0}\right)+c W_{s}\left(1+r+\mu^{j, k}\right)\right] f(r) d r
$$

and we suppose that $f($.$) is a centered normal density with variance \sigma^{2}$. Then:

$$
F^{j, k}(c)=\int_{-\infty}^{+\infty} f(r) d r-\int_{-\infty}^{+\infty} f^{j, k}(r ; c) d r=1-\int_{-\infty}^{+\infty} f^{j, k}(r ; c) d r
$$

where:

$$
\begin{gathered}
f^{j, k}(r ; c)=\exp \left\{-a\left[W_{s}\left(1+r_{0}\right)+c W_{s}\left(1+r+\mu^{j, k}\right)\right]\right\} \frac{1}{\sigma \sqrt{2 \pi}} \exp \left(-\frac{r^{2}}{2 \sigma^{2}}\right) \\
f^{j, k}(r ; c)=\frac{1}{\sigma \sqrt{2 \pi}} \exp \left\{-a\left[W_{s}\left(1+r_{0}\right)+c W_{s}\left(1+\mu^{j, k}\right)\right]\right\} \exp \left(-a c W_{s} r\right) \exp \left(-\frac{r^{2}}{2 \sigma^{2}}\right) .
\end{gathered}
$$

Let us define:

$D^{j, k}(c):=\frac{f^{j, k}(r ; c)}{\varphi(x)}$, where $\varphi(x)$ is a normal density with mean $m_{x}$ and variance $\sigma_{x}{ }^{2}$,

$$
\begin{gathered}
D^{j, k}(c) \varphi(x)=D^{j, k}(c) \frac{1}{\sigma_{x} \sqrt{2 \pi}} \exp \left[-\frac{\left(x-m_{x}\right)^{2}}{2 \sigma_{x}^{2}}\right] \\
D^{j, k}(c) \varphi(x)=D^{j, k}(c) \frac{1}{\sigma_{x} \sqrt{2 \pi}} \exp \left[-\frac{m_{x}^{2}}{2 \sigma_{x}^{2}}\right] \exp \left[\frac{x m_{x}}{\sigma_{x}^{2}}\right] \exp \left[-\frac{x^{2}}{2 \sigma_{x}^{2}}\right]=f^{j, k}(r ; c) .
\end{gathered}
$$

An identification term by term of this last relation, for $x=r$, leads to: $\sigma_{x}=\sigma, m_{x}=-a c W_{s} \sigma^{2}$, and

$$
\begin{gathered}
D^{j, k}(c)=\frac{\exp \left\{-a\left[W_{s}\left(1+r_{0}\right)+c W_{s}\left(1+\mu^{j, k}\right)\right]\right\}}{\exp \left[-\frac{\left(a c W_{s} \sigma^{2}\right)^{2}}{2 \sigma^{2}}\right]} \\
D^{j, k}(c)=\exp \left\{-a W_{s}\left[\left(1+r_{0}\right)+c\left(1+\mu^{j, k}\right)-\frac{a c^{2} W_{s} \sigma^{2}}{2 \sigma}\right]\right\} .
\end{gathered}
$$

We have:

\footnotetext{
${ }^{11}$ Because $U=0$ when the employee exerts his exit option.

${ }^{12}$ Assumption 1 restricts the domain studied to $a w=1$.
} 


$$
F^{j, k}(c)=1-\int_{-\infty}^{+\infty} f^{j, k}(r ; c) d r=1-D^{j, k}(c) \int_{-\infty}^{+\infty} \varphi(x) d x=1-D^{j, k}(c)
$$

Table 1: Summary statistics

\begin{tabular}{lccccc}
\hline \hline \multicolumn{1}{c}{ Variable } & Mean & Std. Dev. & Min. & Max. & N \\
\hline Employee ownership & 1.46 & 1.44 & 0 & 4.97 & 95 \\
CEO's age & 51.05 & 6.38 & 34 & 64 & 95 \\
Founding manager (dummy) & 0.084 & 0.27 & 0 & 1 & 95 \\
Duality (dummy) & 0.42 & 0.49 & 0 & 1 & 95 \\
Months in position & 59.18 & 41.22 & 5 & 146 & 95 \\
Inside CEO (dummy) & 0.6 & 0.49 & 0 & 1 & 95 \\
Relative performance & -0.19 & 1.09 & -3.08 & 1.73 & 95 \\
Ln(Sales) & 7.87 & 1.66 & 4.25 & 10.90 & 95 \\
\hline
\end{tabular}

Table 2: Regression of the level of employee ownership on managers' longevity

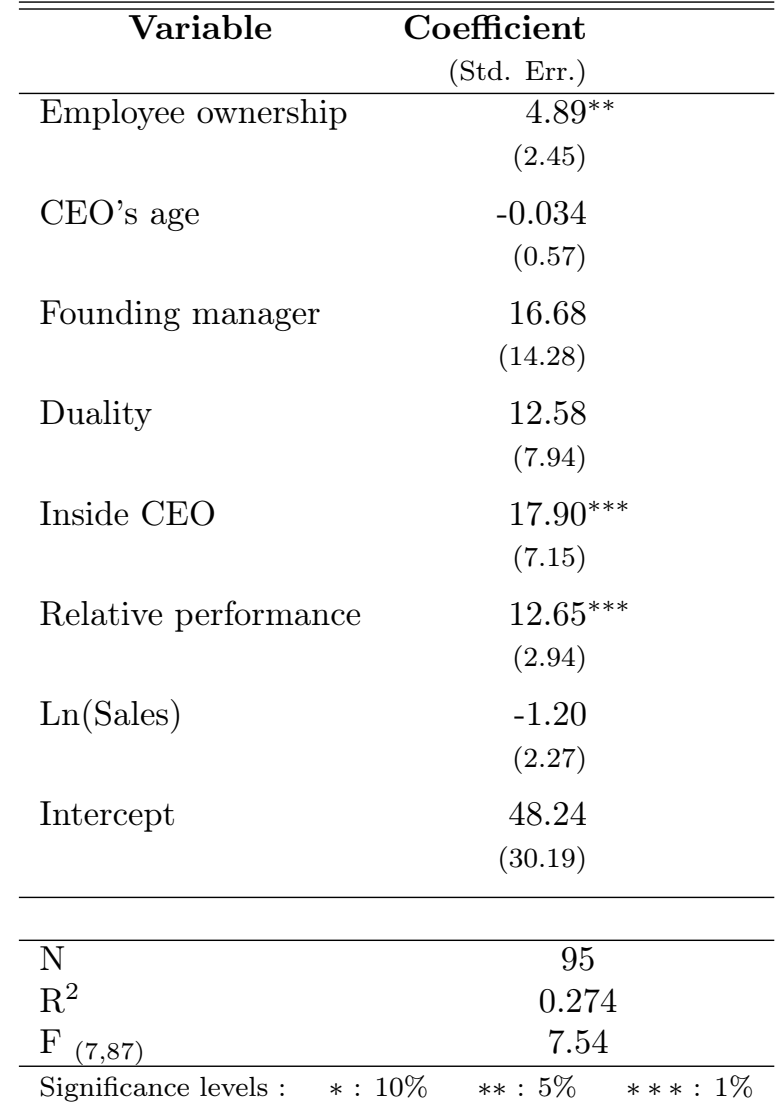

Notes. The dependent variable is the number of months the manager stays in office. Employee ownership is the percentage of equity hold by the employees. CEO's age is measured in years. Founding manager takes the value of 1 is the manager is the founding manager or part of the founding family and 0 otherwise. Duality takes the value of 1 if the board is unitary and 0 otherwise. Inside CEO takes the value of 1 if the CEO worked inside the company before he got in position and 0 otherwise. Manager's relative performance is the difference between the annualized daily stock returns on the company stock and on the sectoral index 
the company belongs to divided by the difference between the annualized volatility of the company stock returns and of the corresponding index. $\operatorname{Ln}$ (sales) in the natural logarithm of the total amount of sales in billion of euros. 


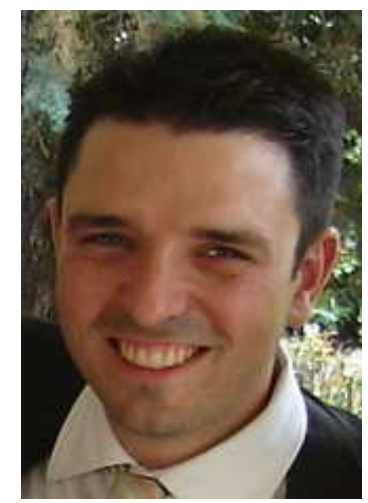

Nicolas Aubert is an Associate Professor of finance at Toulon University (GRM, EA 4177) and an Affiliate professor at Inseec. His main research interests include corporate governance, employee ownership and company based savings plans. He is a research fellow at the French Institute of Corporate Governance (IFGE/EM Lyon).

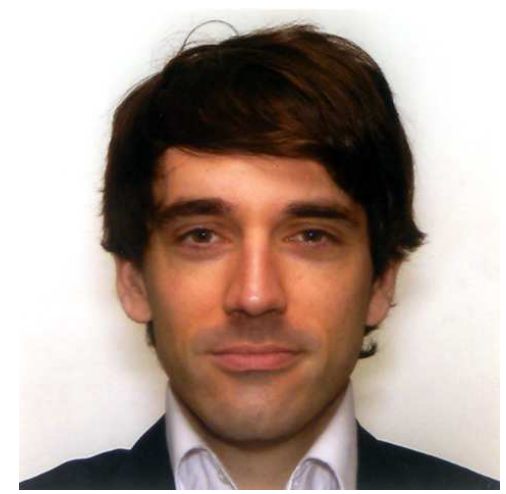

Guillaume Garnotel is an Assistant Professor of Finance at Inseec Business School. His primary research areas include executive compensation policies, ownership structure and the composition of the board. Before coming to Inseec, Guillaume Garnotel received a Ph.D. in Finance from the Aix-Marseille University. 


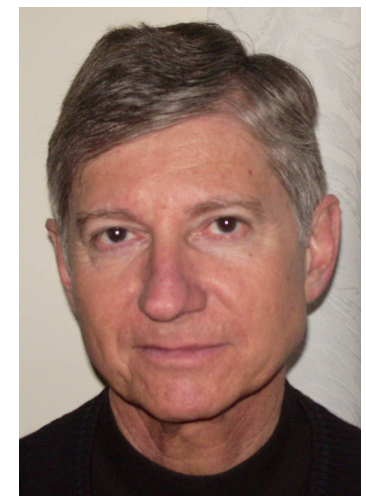

André Lapied is a Professor of economics at Aix Marseille University. He is also a member of GREQAM which is part of the Aix Marseille School of Economics. His main research interests include finance, decision theory and risk. His papers were published in Theory and Decision and Mathematical Social Sciences

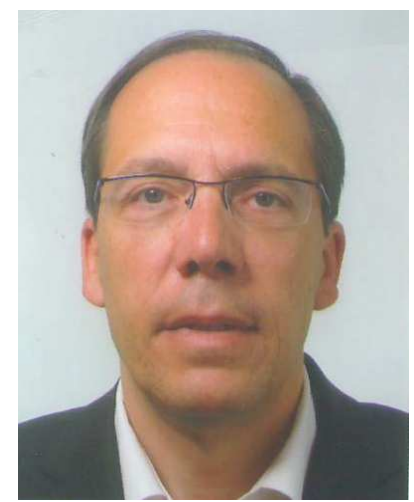

Patrick Rousseau is a Professor of Finance at IAE Aix Graduate School of Management in Aix-Marseille University. He is currently the Dean of the business school. His fields of interest in research are mainly focused on governance and corporate finance. 